\title{
Fray Lorenzo de San Nicolás y la iglesia de Novés (Toledo)
}

\author{
ANTONIO José DÍAZ FERNÁNDEZ
}

De la iglesia parroquial de Novés el Catálogo Monumental de la provincia de Toledo destaca en lo arquitectónico la capilla mayor y crucero del templo, obra que califica de arte ojival del siglo xv, sin que las fuentes documentales que manejara su autor (hoy en parte perdidas) revelaran que el resto de la iglesia, levantada como dice entre 1630 y 1664 , se debiera al arquitecto Fray Lorenzo de San Nicolás '.

Para esta parroquia titulada de San Pedro, continuada en la parte del transepto, que se ha de suponer levantado en el estilo de Alonso de Covarrubias en la primera mitad del siglo XVI, y a cuya vieja fábrica se adosarían también los tres cuerpos de cantería de la torre y la capilla gótico-renaciente en la nave norte, fundada en 1536 por D. Francisco. Castillo, Secretario del Consejo de Su Majestad ${ }^{2}$, el pueblo de Novés (en la jurisdicción de Toledo y a $7 \mathrm{~km}$ de Torrijos) firmaba en 4 de junio de 1651 la escritura de concierto con la Contaduría Mayor de Rentas del Arzobispado de Toledo a fin de reconstruir el resto de la iglesia ${ }^{3}$. Para

1 Conde de Cedillo: Catálogo Monumental de la Provincia de Toledo, Toledo, Diputación Provincial, 1959, pág. 204. El autor tuvo ocasión de consultar datos referentes a la construcción que la sitúan a partir de 1450 , cuando el concejo costea la obra de la cabecera, que se habia de hacer con piedra de las canteras vecinas de "Olveite", mientras el resto del edificio no se llegaba a reformar, aunque reconoce como partes de un momento inmediato de transición al Renacimiento o principios del s. XVI la torre y una capilla lateral con bóveda estrellada.

2 ARCHIVO DIOCESANO DE TOLEDO (A.D.T.), Reparaciones de Templos, Legajo 10, Expediente (expte.) 24. Es la petición de 1730 para reparar el techo de la capilla y en la que consta se dió licencia de construcción en 1536. En el mismo Legajo, el Expte. 11 revela que la torre se recomponía en 1719 con un nuevo chapitel sobre el cuerpo cuadrado de ladrillo, previa demolición de uno ochavado, y según traza de Juan Alvarez Puerta, a la sazón maestro de obras y aparejador de la Sta. Iglesia Catedral; a la vez que se acometían ciertos arreglos en el remate del frontispicio y reparos de consolidación y reboco de cimentaciones.

${ }^{3}$ ARCHIVO HISTÓRICO PROVINCIAL DE TOLEDO (A.H.P.T.), Protocolo (Pr.) 3163, fo 41, escribano (escno.) Rodrigo A. de Hoz. 
ello, el mayordomo de fábrica, Francisco Rodríguez, había solicitado informaciones y diligencias que, una vez autorizadas por el cardenal arzobispo Sandoval y Rojas en septiembre de 1650 y llevadas a efecto en mayo de 1651, precedían el trámite formal para la edificación. Los representantes del municipio, el Mariscal de Castilla D. Juan Hurtado de Mendoza y el presbítero Licenciado D. Andrés Díaz, habían alegado la ruina evidente que presentaba el primitivo cuerpo de iglesia, ante lo cual el Consejo de la Gobernación, órgano administrativo y ejecutivo del Arzobispado con competencias en el encargo de obras de iglesias, determinó la actuación pertinente en estos casos. Se comisionó al Maestro Mayor de Obras de la Santa Iglesia, que lo era Felipe Lázaro Goiti, para reconocer el estado de la iglesia y dar trazas, planta y condiciones técnicas de la obra a realizar. De hecho, en esta escritura de concordia no sólo se dice que el citado maestro mayor tiene dadas cuatro trazas signadas del escribano toledano Rodrigo A. de Hoz, sino que también se afirma que de otro maestro se tenían diseños que obraban en mano de los apoderados de Novés en caso de ser requeridos. En relación a esto, el contador Mayor del Arzobispado, D. Antonio de Velasco, incluía en la citada escritura la cláusula de que los peticionarios pudiesen aceptar o no las trazas de Lázaro Goiti o, por el contrario, aumentar la obra siempre y cuando los excesos sobre la tasación y plan ajustados se costeasen por cuenta del vecindario. Punto éste interesante si seguimos el desarrollo de la edificación, pues motivará la entrada en juego de otro arquitecto.

En 10 de mayo de 1651 la certificación del «maestro mayor de las obras de la Sta. Ygla de T(ole)do y de todas las de su Arçovisp ${ }^{\circ}$ ", a tenor del auto del Consejo de 27 de septiembre del año anterior para el reconocimiento y propuesta de edificación, revela el estado de la iglesia vieja, en la que «todo el cuerpo della esta caydo asi los texados como las paredes ... casi en planta llana". A su vez, Lázaro Goiti declaraba conocer que su antecesor en el cargo había realizado trazas y condiciones para reedificar el cuerpo de naves conforme a la fábrica de la capilla mayor preexistente, idea de la cual no se mostraba partidario al presuponer un gasto mayor en la obra ${ }^{4}$. Por el contrario, proponía levantar un cuerpo de iglesia que obe-

Felipe Lázaro Goiti tomaba el cargo de maestro mayor en agosto de 1643, sucediendo a Lorenzo Fernández de Salazar, que lo desempeñó desde 1631, LLAGUNo y AMIROLA, E.: Noticias de los arquitectos y arquitectura de España desde su Restauración, 4 vol., (facsímil ed. 1829) Madrid, Torner, 1977, t. I, fo 253-254. Si retomamos la fecha dada por el Catálogo Monumental de la Provinca de Toledo para el inicio de la obra del cuerpo de naves en 1630, pensaremos que algún intento de construcción se hizo si no bajo planta de Fernández de Salazar si pudo ser bajo dirección de su antecesor Jorge Manuel Teothocópuli. Confirma esta suposición el hecho de que un en- 
deciera a las dimensiones que estimaba tuvo el anterior, sin añadir ornato, pero haciendo que los pilares cuadrangulares de ladrillo que dividian las tres naves se realizasen redondos y en piedra en función de su perpetuidad $y$ «por que no quiten la vista», adjuntando cinco trazas de las cuales había «una en que se demuestra como se a de fabricar y la una que es la planta demuestra la union de lo antiguo con lo nuebo y en las demas tambien se reconoce lo mismo" (eran, según revela el mismo documento más adelante: una planta, un corte o perfil a lo ancho, un perfil o fachada sur y otro del testero). Lázaro Goiti se reafirmaba en su criterio de utilizar materiales más baratos «si bien a proposito para la seguridad y perpetuydad del edifiçio tambien presento las condiçiones con las quales se an de ejecutar las traças y haçer la obra para que con las dichas traças y ellos se aga el edifiçio nuebo con todo acuerdo puntualidad y seguridad», con una previsión en materiales y mainos de 132.844 reales de vellón.

Lázaro Goiti tenía firmado el pliego de condiciones (a 30 abril 1651) para prevenir tanto el delicado apuntalado de las dos columnas del crucero de la capilla mayor y sus bóvedas como para acometer la fabricación ex novo del cuerpo de naves ${ }^{5}$. Lo excepcional para ese momento es que el arquitecto planteara una iglesia basilical de tres naves, mayor la central, separadas por doce columnas pétreas dóricas que «son las que señala la planta con aguada açul y los çimientos de paredes y estribos son tambien los señalados en diçha planta con aguada açul, por que todo lo demas señalado con aguada parda es lo que esta fabricado antiguo"; levantando sólo los muros sur y oeste con sus pilares de ladrillo y mampostería historiada sobre un zócalo de sillería, y se reforzarían con estribos exteriores de sillares de las canteras de los «Galianos" mientras que la piedra de mampuesto sería de las canteras de Barcience y el ladrillo se prefiere colorado por fuera y rosado por la parte de dentro por estar, a juicio del arquitecto, mejor cocidos que los de color pardo. El alzado interior se haría sobre arcos de medio punto elevando la nave central y cubriéndola con armadura de par y nudillo, pero a una altura por debajo del arco toral del crucero.

Lo cierto es que la reconstrucción de la iglesia de Novés se hubo de emprender de inmediato. Primeramente, ya en 1651, el concejo habilitaba

cargo de retablo y custodia en 1622 advertía de que se hiciera "para quando la yglesia este acavada y desenpeñada", GutiÉRRez García-Brazales, M.: Artistas y artífices barrocos en el Arzobispado de Toledo, Toledo, Caja de Toledo, 1982, pág. 325.

${ }_{5}$ A.H.P.T., Pr. $3163, f^{\circ} 64$. Esta reedificación venía a coincidir en planteamiento con lo que el mismo arquitecto había resuelto en 1647 para levantar el cuerpo e iglesia de la parroquia de Campo Real (Madrid), a cuya cabecera del s. xvi adosó tres naves pero con separación de pilares cuadrangulares y no cilíndricos como en Novés. 
los recursos necesarios para subvenir la obra y libraba los primeros pagos en relación con la misma, habiéndose nombrado en el mes de mayo como cajero administrador de los "pegujares de la iglesia y del trigo" a Jacinto de Aguilar. Mismamente, se ordenaba el pago de 50 reales de vellón al Licenciado Andrés Díaz por diligenciar en Toledo la provisión del Consejo de la Gobernación que ordenase al maestro mayor de sus obras la visita de la iglesia, e igualmente se anotaban 322 reales pagados "a el $\mathrm{m}$ [aest]ro. mayor y a fray laurençio quando binieron a la bista de la obra para hacer el informe a el Consexo en que enttra el gastado que se hiço con ellos", aunque realmente serán 680 reales los señalados a Lázaro Goiti por el trazado de la obra y el consiguiente informe remitido al Consejo arzobispal ${ }^{6}$.

Indiscutiblemente, la intervención de un segundo arquitecto, precisamente el agustino Fray Lorenzo de San Nicolás, se hace obvia desde el primer momento en franca competencia con el maestro mayor designado por el arzobispado, cuyo proyecto quedará relegado como se reconoce más adelante en una partida de pagos a oficiales de la obra, donde se apunta la cantidad de 70 reales entregados a «Fran ${ }^{\circ}$ de mora maestro de obras $v^{\circ}$ de Casarrubios por benir a acer la obra y traças dadas por el padre fray laurençio en que entra el gasto que iço y de la perssona que fue de [...] a Diego Lopez escriv ${ }^{\circ}$ deste lugar de acer la ynformaçion de la rrenta que tenia la yglessia". $Y$ entre 1651 y 1654 se habian sacado ya veinticinco carros de piedra y suministros de cal para principiar la obra.

La construcción tomaba un nuevo carácter al encargar el concejo de Novés el proyecto al acreditado arquitecto madrileño y a sus maestros de confianza en detrimento de las propuestas ciertamente conservadoras de Felipe Lázaro Goiti, que fallecía en $1653^{7}$. Esto es así puesto que Juan de Corpa, maestro de obras de Madrid, está con su equipo de oficiales y peones en la obra de la iglesia de Novés al menos desde el 26 de junio de 1652, y se le libraba por el trabajo de un año la cantidad de 6.455 reales; otro sí, los 189 reales que cobró Francisco de Villanueva por orden del mismo Corpa, al estar encargado durante un mes del derribo de los muros

\footnotetext{
- ARCHIVO MUNICIPAL DE NOVÉS (A.M.N.), Libro de Cuentas (1650-1676), f $32 \mathrm{v}$. Cuentas dadas en 5 de mayo de 1651. Este libro contable es el único documento relacionado con la obra de la iglesia, costeada por el municipio, puesto que el Archivo Parroquial no conserva libros de fábrica de ese periodo y el cuerpo notarial de protocolos, incorporado al de Torrijos, desapareció en la Guerra Civil, de 1936-39, lo que nos impide encontrar los contratos de obligación y condiciones de obra.

7 Revenga Domínguez, P.: «Felipe Lázaro de Goiti, Maestro Mayor de la catedral de Toledo", Academia, n 68,1989 , págs. 117-152.
} 
viejos, entre junio y julio de 1653. Gran actividad nos revelan las partidas de gastos del libro de cuentas de la fábrica al incluir 4.501 reales «que por carta de pago parece aver dado al Padre Fray laurençio de san nicolas de las veçes que bino açer bissita de la dha obra y a la perssona que con cabalgaduras ttraxo arena y ladrillo y cal que él compro y pagar oficiales que an travaxado en dha. obra y esto a sido asta seis dias del mes de avril passado deeste año de $53{ }^{\prime}{ }^{8}$. Desde marzo hasta julio, el maestro de cantería Pedro de Vela estaba trabajando con sus oficiales la piedra sacada y porteada por él mismo; 19.870 ladrillos llegaban a pie e obra, mientras el yeso se empleaba en los tabicados que aislarían la cabecera y la capilla de los «Castillo».

Hasta febrero de 1656 se suceden nuevos gastos que indican la buena marcha de los trabajos iniciales de demolición y apeo y posiblemente de cimentación. Así, a los 1.406 reales que recibía «Joan de Corpa de la copia de cinco semanas de peones y xornales de maestros que travaxaron en dha. obra, cal y clavos", se sumaban 1.465 reales de otras dos semanas de trabajo, salarios, materiales y herramientas y «de la benida del Padre Fray lauren ${ }^{\circ}$. a ver la obra" ${ }^{9}$. Juan de Corpa y el maestro Juan Rico cobraban de nuevo por diez semanas de ocupación 2.595 reales y Fray Lorenzo recibía ahora los 866 reales de su asistencia en agosto de 1650 , quizás la primera de las visitas a Novés. Otro pago de 1.839 reales "que por rescivo de Fray Laurençio de san nicolas pareze aver dado a $\mathrm{P}[\mathrm{edr}]^{\circ}$ de bela mro. de canteria de sus jornales», y a quien se debe la labra de jambas y dinteles y su colocación en «ambas portadas de la yglesia", ya en julio de 1654 , acto que se celebró con festejo y gasto de vino.

Un nuevo período contable, entre ese año y junio de 1657, omite cualquier incidencia en el curso de las obras, no así en los tres años siguientes, en que se consignan algunas partidas relacionadas con la obra pero se percibe la precaria situación de los trabajos, acusándose una paralización real de la construcción ${ }^{10}$. En realidad, se había entrado en un proceso judicial, abierto para dilucidar las circunstancis de una irregular administración de los fondos unido al hecho de que «por causa de aber suçedido una muerte de un vecino de este lugar por una pessadumbre que

A.M.N., Libro de Cuentas (1650-1676), $f^{\circ} 55 \mathrm{v}$.

- Ibidem, $f^{\circ} 68$. No es posible precisar cuándo exactamente giró esta visita el arquitecto, aunque el pago pudiera corresponder a 1654; de cualquier modo, su asistencia a los comienzos de la obra hubo de ser muy regular.

${ }_{10} \mathrm{Ibidem}, \mathrm{f}^{\circ} 103$. Sólo se acusa una compra importante de 30.000 labores de ladrillo «puesto en la yglesia", por un total de 86.700 maravedíes. 
tubo con los oficiales que trabaxaban en dha obra», la misma se hallase detenida desde agosto de $1654^{11}$. Y haciendo declaración en este mismo proceso, el maestro de obras de Novés Damián Ordoñez, reconocia en 13 de mayo de 1660 estar «lebantada una nabe asta el movim[ien]t ${ }^{\circ}$ de los arcos quedandole por açer las dos partes mas de lo hecho para poder cubrir y el lado de la puerta que esta en la nabe principal no esta mas que asta la altura de las puertas que sera de alto cuatro baras poco mas o menos y lo demas de la obra esta por empeçar todo lo qual es causa de mucho daño a la capilla mayor y a las demas capillas que estan alrededor", evaluando el coste de lo realizado en 36.038 reales ${ }^{12}$.

En agosto de aquel año el concejo de Novés y el administrador de la obra y fábrica solicitaron al Arzobispado la provisión para vender trigo a fin de «que se les socorra a los dhos maestros y peones y canteros y para lo demas que fuere necessario y peones y canteros y para lo demas que fuere necessario de materiales para que no cese la obra y fabrica [...] oy es el tiempo oportuno y el que conbiene se fabrique que de dilatarlo llegara el ynbierno y no se podra acer" ${ }^{13}$. Con el decreto del Consejo de Gobernación de 15 de octubre de 1660 las obras se reanudaron con nueva fuerza al año siguiente, habiendo rematando el encargo de ia construcción en los maestros de albañilería Damián Ordoñez y el toledano Juan de Herrera, a quienes se habían dado en agosto de ese año 2.169 reales en cuenta de lo que recibirían por acabar la obra, e interviniendo en 1662, con acuerdo de este último, el alarife de Toledo Diego (Sánchez) de Medina para dar parecer del derribo de unos arcos desplomados ${ }^{14}$. La compra de materiales también aumenta, adquiriéndose 10.000 ladrillos, arena y cal de Malpica; desde 1667 se concierta el labrado de trescientos

1 A.D.T., Reparaciones de Templos, Leg. 19, Expte. 28, $\mathrm{f}^{\circ} 12$, «Autos... sobre que se reconociese el estado de la obra de la parroql. de Noves y se tomasen cuentas $p^{a}$ averiguar en quien paraban los $m$ [aravedie]s consignados para dha obra". Esta contingencia en el transcuso de las obras la revela el testimonio del clérigo Miguel Ramírez, de 74 años, uno de los varios testigos que intervienen en los autos judiciales y el único que da fe de esta fatalidad en relación con la obra.

${ }_{12} \quad$ lbidem, $4^{\circ} 13 \mathrm{v}$. Este maestro local, de 38 años de edad confesados, se remitía al contenido de otro informe de noviembre de 1658 que demostraba que la iglesia se encontraba en el mismo estado sin que la obra hubiese avanzado nada.

1.3 A.M.N., Libro de Cuentas (1650-1676), $f^{\circ} 108$.

14 Sobre el maestro de albañilería toledano Juan de Herrera sabemos que había estado dirjgiendo la construcción de tres importantes obras en Toledo, bajo trazas de distintos arquitectos: la iglesia de Benitas de la Concepción (1652-1657), la iglesia de las "Gaitanas" (desde 1656) y la de Capuchinas (1665-1674) (SuÁREz QueVEDo, D.: Arquitectura barroca en Toledo, siglo xVII, Toledo, Caja de Toledo, 1990, págs. 155, 158, 180, 190). También se ocupaba, en unión del maestro Diego de Medina, de la gran reforma de la iglesia parroquial de Santo Tomé, entre 1661-1666, obra tasada por D. Bartolomé Zumbigo y Juan Ramos (de Vega) (Ramírez de Arellano, R.: Catálogo de artifices que trabajaron en Toledo, Toledo, 1920, pág. 141). 
pinos comprados en Cenicientos; en 1669 se consume yeso moreno para los enfoscados de la bóveda de la nave central y yeso para los enlucidos, además del pago de 39.236 maravedías a los canteros Antonio de Mendoza y Marcos Castaño por la obra de «las piedras $\mathrm{p}^{\mathrm{a}}$ las piramides y cruz que an labrado para el frontispicio de dha yglessia».

Según el mismo libro de cuentas, entre 1670 y 1675 las obras se estaban ultimando aunque se precisaba hacer un contrafuerte en la fachada occidental. Mientras, Francisco González, maestro de albañilería de Toledo y "yerno de Juan de Herrera», recibía 6.400 reales por el trabajo de oficiales y peones para voltear las bóvedas de las naves laterales, jaharrarlas y blanquearlas, pagándose el yeso empleado a Juan Ordoñez, hijo y albacea de Damián Ordoñez; y, de igual modo, se acometía ya el solado de la iglesia y la formación de la tribuna a los pies.

En junio de 1670 el Arzobispado supervisó el estado adelantado de las obras comisionando a Cristóbal Rodríguez de Xarama, maestro mayor de obras de la Dignidad en estos años, para visitar Novés y evaluar lo hasta entonces realizado en la iglesia parroquial, quien, teniendo por referencia «las condiciones que para ella yço Phe-. Lazaro de Goite (sic) mro. que fue, a allado que no am cumplido con ellas aunq- lo fabricado esta en buena disposiçion = eçepto el ultimo arco de la nabe de medio dia que es el que cahe junto a la tribuna, que esta haziendo biçio y sentimiento conozido por defecto de çimiento y estribo", ordenando la urgente entibación en el plazo de tres meses ${ }^{15}$. La realización de esta obra menor pero inexcusable, que no terminaba de obedecer a la traza de Rodríguez, propició una nueva vista de ojos que el Contador Mayor encomendó en enero de 1671 a D. Bartolomé Sombigo y Salcedo «ayuda de traçador y maestro mayor de las obras Rs. de su Mag-», para reconocer la iglesia de Novés en virtud de las condiciones del que fuera maestro mayor Lázaro Goiti, de

15 A.D.T., Reparaciones de Templos, Leg. 10, Expte. 23, “Novés año de 1670. Sobre que cumplan las condiciones con que se obligaron a executar los reparos de la Parroq a de dho. lugar». De Rodríguez de Jarama se dice aquí ser vecino de Valdemoro, pero su cargo de maestro mayor no parece estar en Toledo sino en algún partido dependiente de la Dignidad Arzobispal que no se expresa. En el peritaje que hace en Novés extraña que se guiara por las condiciones de Lázaro Goiti estando advertido de que la iglesia se venía construyendo según plan de Fray Lorenzo como lo atestigua el hecho de que en la visita, que tuvo lugar en 12 de diciembre, declaraba haber «bisto el estado y forma que tiene dha obra de dha ygl ${ }^{\mathrm{a}}$ y la cantidad de $\mathrm{m}$ [aravedie]s que fray laurençio de san nicolas recivio de lo que obro y lo que an rrecivido a qta. de los mrs. en que esta concerttada [...] con Joan de Herrera y damian ordoñez mtros. de albañileria» (A.M.N., Libro de cuentas (1650-1676, s/f). Aún faltarian años para realizar en Aranjuez su obra más representativa, la iglesia de Alpagés (1681), siendo entonces maestro de obras de S. Lorenzo, GaRcía PARAmo, A.M ${ }^{a} .:$ «Iglesia de Alpajés, en Aranjuez», A.I.E.M. VII, 1971, pág. 174. 
lo obrado según trazas de Fray Lorenzo y del último dictámen de Cristóbal Rodríguez. La declaración de Sombigo, en contra del obrar del maestro cantero Jerónimo de la Vega «residente en dho lugar», no puede ser más concluyente al verificar «en quantto a lo fabricado esta executtado lo que oy esta echo en conformd. de planta y traças de fray nicolas de san lorenço digo fray lorenço de san nicolas [sic] y condiciones que son con las que dho lugar dio principio a la dha obra y la ba continuando y falta para rematar y acavar dha obra las bobedas de las dos naves colaterales para darles el blanqueo de las paredes y jaarros de ellas y las puertas de madera y una portada de piedra a la parte del norte", confirmando el desplomo de la pared sur sobre la puerta de los pies en cuyo reparo proyectó Rodríguez de Jarama el botarel de piedra, entonces por terminar y a lo que estaba obligado el concejo e iglesia de Novés para dar definitivamente por concluida la iglesia "en confor[mida]d de las traças y condiciones de el dho fray lorenço de s. Nicolas que son las que este dho lugar elixio de su autoridad para fabricar dho cuerpo de yglessia y naves como consta por la scriptura de su obligacion a favor del Sr. Contador mayor de Rentas dezimales» ${ }^{16}$.

De principios de agosto de 1677 es la petición de $\mathrm{D}$. Pedro de Rodrigo Alonso, cura propio de la parroquial de Novés, solicitando al Cardenal Pascual Aragón se considerase concluida la obra de la iglesia sin que sea necesario abrir la portada norte que se preveía, puesto que en ese lugar estaba ya autorizado levantar una capilla particular; petición que se repite dos años más tarde, en el mes de mayo, solicitando de nuevo a Su Eminencia provisión para que un maestro reconociese la obra ejecutada y si estuviese conforme diera por concluida la obra con lo que, de este modo, el pueblo de Novés pudo disponer de iglesia nueva probablemente desde $1680^{17}$.

La elección del plan de Fray Lorenzo de San Nicolás abrió una nueva perspectiva arquitectónica que el concejo de Novés, como parte directa

15 lididem, s/f. Bartolomé Zumbigo o Sombigo, era desde 1654 Ayuda de Trazador Mayor de las Obras Reaies y también desempeñaba el cargo de Aparejador de los reales Alcázares de Toledo, siendo en junio de 1671 cuando en él recayó el nombramiento de Maestro Mayor de las Obras de la Santa Iglesia Catedral, Rodriguez Martín, J.M.: El Arquitecto toledano Bartolomé Sombigo y Salcedo (1620-1682), Toledo, Excmo. Ayto., 1989.

17 A.D.T., Reparaciones de templos, Leg. 10, Expte. 36, «Novés año 1679». En la nave norte se empezaron a abrir distintas capillas junto a la antigua de los "Castillo", como la del Cristo del Remedio (1664), la del Rosario, la de los Remedios (1674, fundada por Pedro Rodríguez Trabado). Para declarar el final de la obra se comisionó al aparejador de la catedral Pedro González, que reconociese el estado de la iglesia. 
en el encargo de la obra, asumió a pesar de la retirada inopinada de Juan de Corpa, el colaborador directo y discípulo del arquitecto agustino, con el consiguiente entorpecimiento de la marcha de la empresa constructiva y el inevitable inicio de un litigio entre el ejecutor de la obra y los comitentes ${ }^{18}$.

En este sentido, de 1660 es la escritura de poder por la que Juan de Corpa nombraba a Fray Lorenzo de San Nicolás «rresidente en la ciudad de Toledo para que por mi y en mi nombre pueda nonbrar persona o maestro de obras que acave la obra que tengo començada en el lugar de noves, jurisdicion de la dha Ziudad de Toledo» y pueda cobrar lo que se tasare por la obra realizada, con lo que parece apartarse decididamente de la misma ${ }^{19}$. Y más adelante otorgará su poder insolidum al propio Fray Lorenzo y al procurador de Toledo Francisco de Rojas para demandar al concejo y mayordomo de Novés y a la fábrica de su iglesia parroquial cualquier cantidad adeudada en razón de lo obrado a su cargo ${ }^{20}$. En ese mismo año y en relación a este seguimiento del pleito, Fray Lorenzo de San Nicolás «estante a el presente en su conbento de la çiudad de Toledo" otorgaba su pleno poder al citado procurador «en raçon de lo que monta la obra que de mi horden hiço en la yglessia del dho lugar Juan de Corpa maestro de albañileria» ${ }^{21}$.

Como parte interesada en el pleito, el Consejo de la Gobernación del Arzobispado de Toledo pretendería indagar sobre la situación de la obra y, dispuesto a proseguirla, se precisaba acudir en ese mismo año a Madrid para ver a Fray Lorenzo con el fin de renovar la escritura de obligación de la obra y para que pusiese maestro que la hiciera al haber cesado en su dirección Juan de Corpa ${ }^{22}$. Este maestro, por orden de la justicia ordinaria

18 La retirada de Corpa parece incluso más temprana pues en el testamento que otorgaba en Madrid, en 3 de septiembre de 1660, es una de las cláusulas dice «me an envyado a pedir del lugar de nobes un tabernero que sera aora ocho años del dho lugar que por no estar çierto en su nombre no le declaro aqui, una cantidd de asta veinte y seis Rs y por no estar çierto si se los devo o no mando que cargo de su conçiençia si se los pidiere sse le paguen", ARCHIVO DE PROTOCOLOS DE MADRID (A.P.M.), Pr. 9984, fo 165, escno. Luis Martínez de Porras.

19 A.P.M., Pr. $8687, f^{\circ} 26$, escno. Juan Tomás de Torre. Poder para cobrar dado en Madrid a 11 de abril de 1660 .

20 Ibidem, $\mathrm{f}^{\circ} 33$. Poder de 24 de junio de 1660.

21 A.H.P.T., Pr. 3485, $f^{\circ} 415$, escno. Sebastián López. Poder con fecha 2 de julio de 1660 . En sus estancias en Toledo Fray Lorenzo residía en el convento de Recoletos agustinos, desamortizado en el s. XIX y en cuyo solar se edificó un hotel en estilo revival, quedando hoy en el callejero el nombre de Recoletos.

22 A.M.N., Libro de Cuentas (1650-1676), f ${ }^{\circ}$ 104-105v, año 1660. Se advierte una constante movilidad de Fray Lorenzo entre Madrid y Toledo, y tal vez se hallara antes de abril o en el mes de mayo en la Corte, a donde acudió D. Juan de Monroy, por orden del concejo de Novés, para formalizar la nueva escritura de obra. 
de Toledo, envió al maestro de obras en esa ciudad, Juan Ramos de la Vega, para medir y evaluar el estado de la obra, mientras que por otro auto del Corregidor toledano comparecía para la misma tarea el alarife Diego de Benavides, peritos que habrían de hacer la tasación requerida judicialmente ${ }^{23}$.

Por su parte, en 1663, será el vecino de Novés Melchor de Solórzano, mayordomo de la obra entre 1653 y 1656, el que otorgaría su poder a los procuradores de Toledo Francisco Rojas, Andrés de Baillo, José Rodríguez y Martín Ortiz para actuar en el pleito que contra él trataba Corpa ${ }^{24}$; y en el mes siguiente comparecía el primero de estos procuradores, esta vez en nombre del maestro de obras, para trasladar su poder a Francisco Sorribes, procurador en la Real Audiencia y Chancillería de Valladolid, en donde se habría de dictar la resolución definitiva de la disputa ${ }^{25}$.

Ya desde Madrid, Fray Lorenzo seguía el pleito en 1667 y, usando de licencia del Provincial Fr. Juan de la Madre de Dios (29 de marzo de 1664), daba su poder, en 15 de febrero de aquel año, al procurador Rojas y al hermano fray Alonso de Santa Catalina, sacerdote residente en el convento agustino de Maqueda, con el fin de cobrar «la obra que a echo en la yglesia del lugar de nobez, jurisdicion de Toledo», revocando con ello un poder anteriormente otorgado a Fr. Juan de la Encarnación con el mismo efecto ${ }^{26}$.

Con posterioridad, sabemos que en 1668 el concejo y fábrica de la iglesia de Novés entregaban a Fray Manuel, portador de la ejecutoria ganada por Fray Lorenzo en Valladolid, la cantidad de 2.478 reales que según tasación de los maestros peritos se le estaba debiendo de la obra y con lo que el pleito quedaba dirimido en derecho y forma ${ }^{27}$.

23 Ibidem, $f^{\circ} 131 \mathrm{v}-132$. Aquí, el escribiente confunde a Diego Benavides citándolo como juan Ramos Benavides. Sin embargo, ambos maestros de obras, Benavides y Ramos, eran bastante conocidos y muy activos en el medio toledano.

${ }^{24}$ A.H.P.T., Pr. 3487, f 93 , escno. Sebastián López. Poder dado en Toledo a 24 enero de 1663.

${ }^{25}$ Ibidem, fo 101. Fechado en 14 de febrero de 1663. Novés, a través del jurado y escribano toledano Sebastián López, hace remitir los autos y diligencias del pleito a la misma Chancillería, a finales de 1663, A.M.N., Libro de Cuentas (1650-1676), $\mathfrak{f}^{\circ} 157 \mathrm{~V}$.

${ }^{26}$ A.P.M., Pr. 9985, $f^{\circ} 456$, escno. Luis Martínez de Porras. Más adelante, en $f^{\circ} 510$, escritura de poder de 24 de junio de 1667, a favor de Fray Francisco de San José, prior del Convento de Agustinos Delcalzos de Toledo, del Padre Fray Manuel de la Madre de Dios, presbítero del convento, y del procurador Francisco de Rojas.

27 A.M.N., Libro de Cuentas (1650-1676), f० 195. 
Antonio Ponz, a su paso por Novés camino de Talavera de la Reina, pudo hacer un breve apunte al decir que la iglesia de S. Pedro "compuesta de tres naves, es espaciosa, y la capilla mayor, que tenía sus antiguos ornatos a la gótica, está echada a perder con chafarrinados de colores sin venir al caso", aunque sin pronunciar mayores elogios pero advirtiendo la calidad del edificio en sí $^{28}$.

Pues bien, la iglesia parroquial de Novés se suma al catálogo de obras realizadas por el agustino recoleto Fray Lorenzo de San Nicolás (15951679), a quien hemos de considerar no sólo un arquitecto madrileño sino también un arquitecto toledano, debido tanto a la circunstancia de su filiación y formación paterna (sabido es que su padre, también maestro de obras, de quien aprendió Fray Lorenzo el oficio, era natural del pueblo toledano de La Mata y murió en Toledo hacia 1647) ${ }^{29}$, como también a sus numerosas intervenciones en edificios de Toledo y su provincia. Esta toledaneidad del acreditado arquitecto y tratadista agustino está avalada por obras ya conocidas o estudiadas como son las trazas que hizo para la cúpula de la iglesia conventual de las jerónimas de la «Vida Pobre» (1638-1656) y para la iglesia del convento de las agustinas calzadas o "Gaitanas» (1633) en la capital ${ }^{30}$. En Talavera de la Reina desde 1625 ideó otras tantas iglesias conventuales, pero destacando tal vez la capilla mayor del santuario de Nuestra Señora del Prado (1649) ${ }^{31}$. En Villaseca de la Sagra formó el plan para la capilla-panteón del hospital de S. Bernardo, con ejemplar cúpula encamonada, y para la iglesia parroquial, el cuerpo de naves y la torre, habiendo dado también para la vecina Añover de Tajo la traza de su torre parroquial, tres obras concebidas en

\footnotetext{
${ }_{28}$ PONZ, A.: Viaje de España, (facsímil ed. 1800) Madrid, Aguilar, 1988, vol. 2, t. Vll, pág. 365.

${ }^{29}$ Llaguno y Amirola: Op. cit, $t$. IV, $f^{\circ} 22$. El padre, que en la Orden se llamó Fray juan de Ntra. Sra. de la O, se encargó en Toledo de la edificación de la iglesia y convento de Agustinos Recoletos, que le ocupó desde 1637 hasta su muerte; edificio desaparecido que no ha dejado memoria de su arquitectura y en el que es probable interviniera en años posteriores su hijo.

30 SUÁREZ QUEVEDO: Op. cit.; aunque de por sí, el propio Fray Lorenzo lo testimonia en la primera y segunda parte de su tratado Arte y Uso de la Arquitectura, publicadas en 1636 y 1664 , respectivamente. Marias, F.: Arquitectura del Renacimiento en Toledo (1534-1634), Madrid, C.S.I.C., 1986, t. III, pág. 177. Rodriguez Martín: Op. cit., pág. 145. En la “Vida Pobre», convento desaparecido en 1808, parece confirmada su intervención pues en julio de 1661, estando en Toledo, Fray Lorenzo había dado condiciones y precios para continuar la obra de la iglesia, encargándose de la ejecución el maestro de obras toledano Juan Ramos de Vega.

3i López Gayarre, P.A.: Arquitectura religiosa del siglo xVII en Talavera de la Reina (Fray Lorenzo de San Nicolás y su influencia), Toledo, Excmo. Ayto. de Talavera, 1989, pág. 83. La estancia en Talavera como "Maestro de Obras del convento agustino" se dataría entre 1625 y 1649. En esta villa, es el alarife Sebastián Calvo el maestro que participa en muchas de estas obras laurentinas.
} 
torno a $1650^{32}$; y antes diseñaba en 1632 otra torre parroquial para el pueblo de los Navalmorales ${ }^{33}$.

Y por demás, como aquí se ha comprobado, Fray Lorenzo de San Nicolás intervino en el planteamiento y supervisión de la construcción del cuerpo de naves de la iglesia de Novés desde 1651, asumiendo el encargo con el maestro de obras de Madrid Juan de Corpa, si bien hemos advertido que la ejecución de la obra sobre las trazas de Fray Lorenzo la principió el maestro de obras y vecino de Casarrubios del Monte, villa próxima a Novés, Francisco de Mora ${ }^{34}$.

La iglesia parroquial de Novés se encuentra emplazada en sitio abierto y elevado, constituyendo un edificio exento de grandes proporciones. Al exterior, en el imafronte sobresale del plano de fachada la torre cuadrada, de tres cuerpos de sillería caliza y recrecida por campanario de ladrillo, que resguarda la portada principal (Fig. 1); mientras que en la cabecera destaca la pesada fábrica en piedra de la capilla mayor, de planta poligonal con sus contrafuertes y ventanales de tradición ojival abiertos en los testeros del transepto protorrenacentista. Entre la torre y la cabecera el resto del edificio está formado por el buque de naves, construido en albañilería y mampostería, que delata ser la obra diferenciada que aquí hemos documentado perteneciente a la segunda mitad del siglo XVII.

En planta, esta parte de iglesia responde a un cuerpo cuadrilongo de naves longitudinales, algo más ancha la central y con capillas laterales abiertas a la nave norte; por tanto, obra barroca adosada a la cabecera gótica-renaciente en un esfuerzo por trabar y armonizar arquitectónicamente construcciones bien distintas (Fig. 2).

La obra de Fray Lorenzo consiste pues en tres naves compartimentadas, separadas por pilares de sección cuadrangular sobre los que cabalgan arcos de medio punto de amplia luz, abiertos a los cuatro tramos de la nave

32 Diaz FERnÁndez, A.J.: "Obras del arquitecto Fray Lorenzo de San Nicolás en Villaseca de la Sagra (Toledo)", Anales Toledanos, 1989, págs. 233-275. En estas tres obras trabajó simultáneamente Pedro Díaz Mejorada, maestro de obras que era aparejador y sobrestante en el Real Sitio de Aranjuez.

33 Conde de Cedillo: Op. vit., pág. 200. Revenga Dominguez: Op. cit, pág. 139.

34 Este maestro es el que aparece como fiador de Juan Bautista Garrido, maestro de arquitecto vecino de Madrid, en la obligación de obra de un retablo para Ntra. Sra. del Rosario para ia iglesia parroquial de S. Andrés de Casarrubios, firmada en 13-11-1635, Agullo y CoBo, M.: Documentos sobre escultores, entalladores y ensambladores de los ss. XVI a XVIil, Valladolid, 1978, pág. 72. Este homónimo del conocido arquitecto real fue el maestro de obras que tuvo a su cargo la obra de torre y sacristía de la iglesia toledana de Carranque en torno a 1645 (A.D.T., Reparaciones de templos, Leg. 14, Expte. 4). 


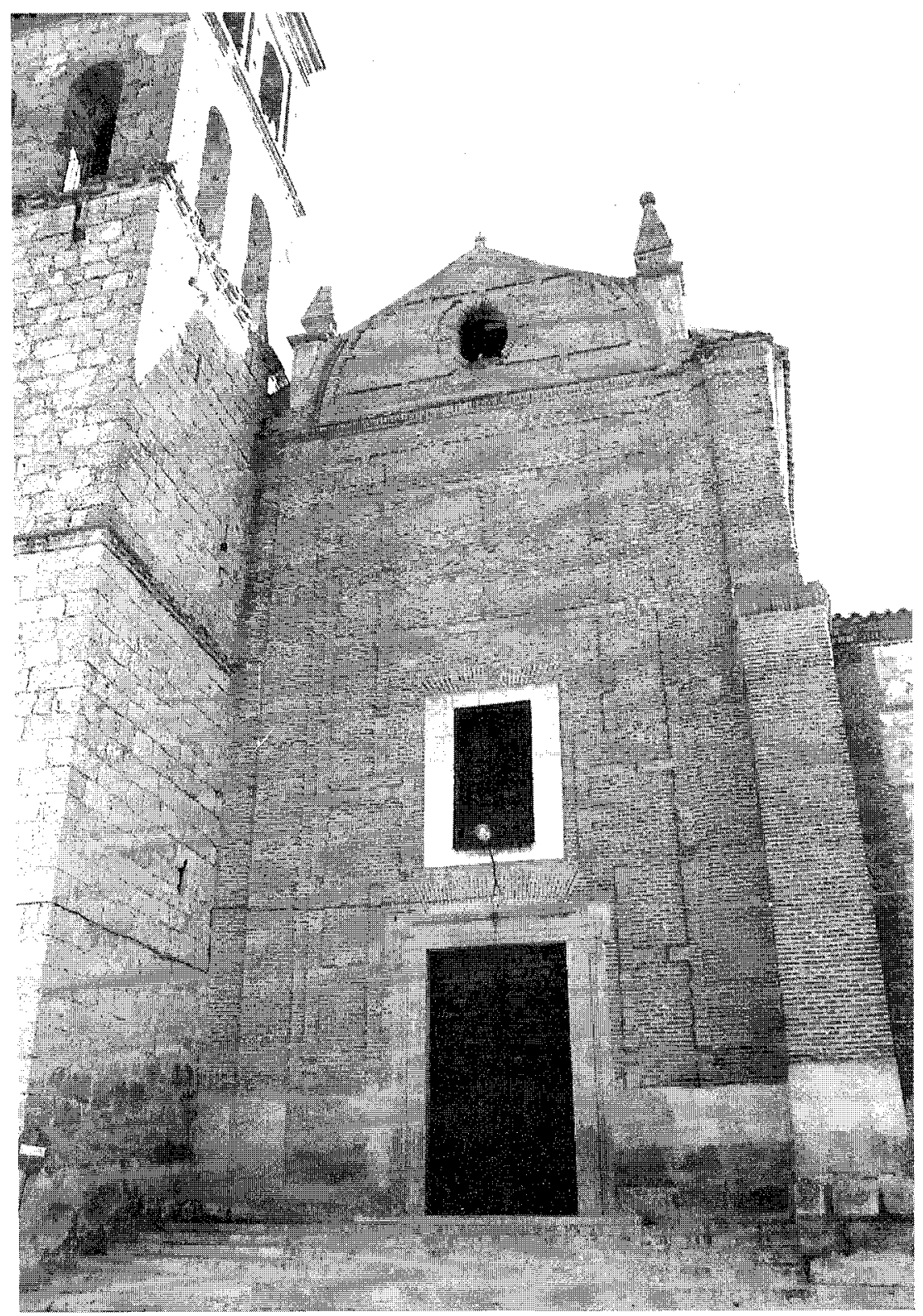

Fig. 1. Fachada principal de la Iglesia Parroquial de Novés. 


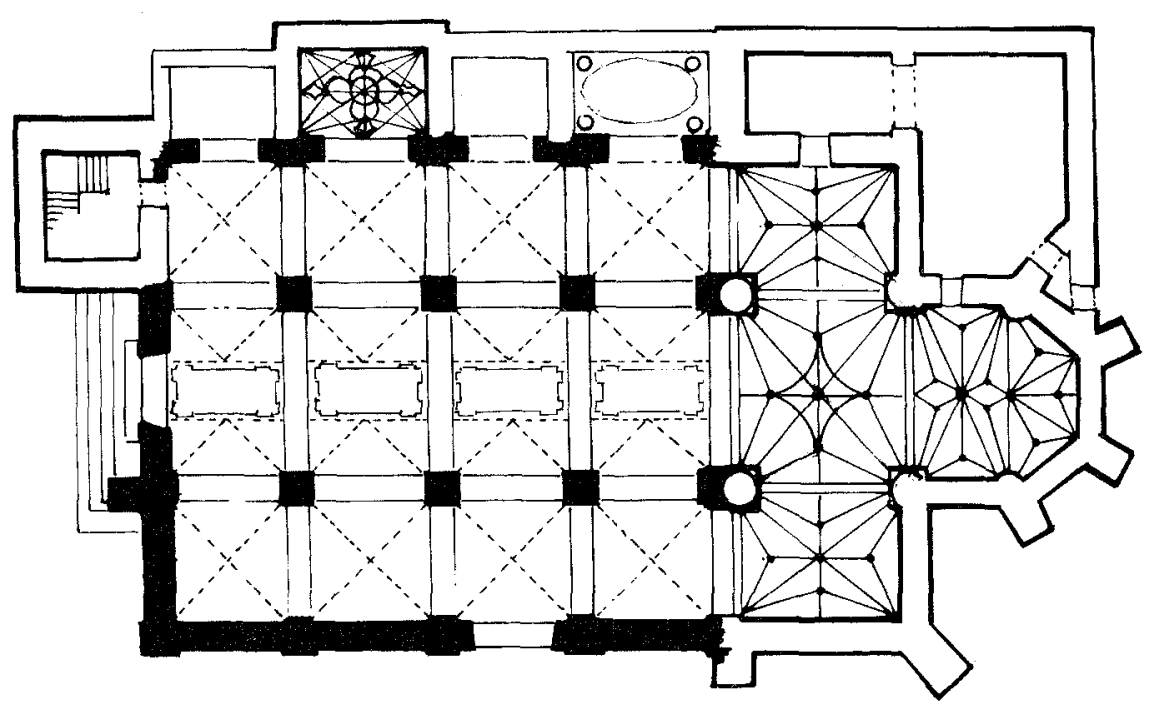

Fig. 2. Croquis de Planta (sombreado, lo construido en el S. xVII).

central, más elevada y cubierta con bóveda de cañón dividida por arcos y lunetas, mientras que los tramos cuadrados de las naves laterales lo son con bóveda de aristas, no superando en altura el nivel de cornisas de la nave central. El coro o tribuna se alza entre los dos arcos formeros del tramo ulterior de la nave y sobre arco rebajado. Las luces sólo se abren, ciegos los del norte, en los lunetos del flanco sur de la bóveda central, lo que desequilibra ciertamente el efecto lumínico sobre el espacio longitudinal central.

En cuanto su alzado, señalamos que esta nave central se articula sencillamente con un orden córico de pilastras superadas por entablamento corrido en el que se recurre a un simple friso de triglifos, en este caso sin metopas, y una cornisa de poco vuelo sobre dentículado, cuya impostación enrasa con el ábaco de los capiteles dóricos de los dos pilares-columnas del crucero (Fig. 3). Cada tramo de la bóveda central se divide en tres partes iguales: a los extremos los triángulos de los lunetos y en el centro, en el sentido longitudinal se desarrolla como elemento de adorno un marco de labor plana y de ángulos acodados, con recuadro rectangular. En las naves laterales la articulación se realiza resaltando puramente los perfiles y severas líneas estructurales.

El acceso a la iglesia se hace por dos únicas portadas planas con sus jambas y dintel de piedra caliza, decoradas igualmente con moldura con- 


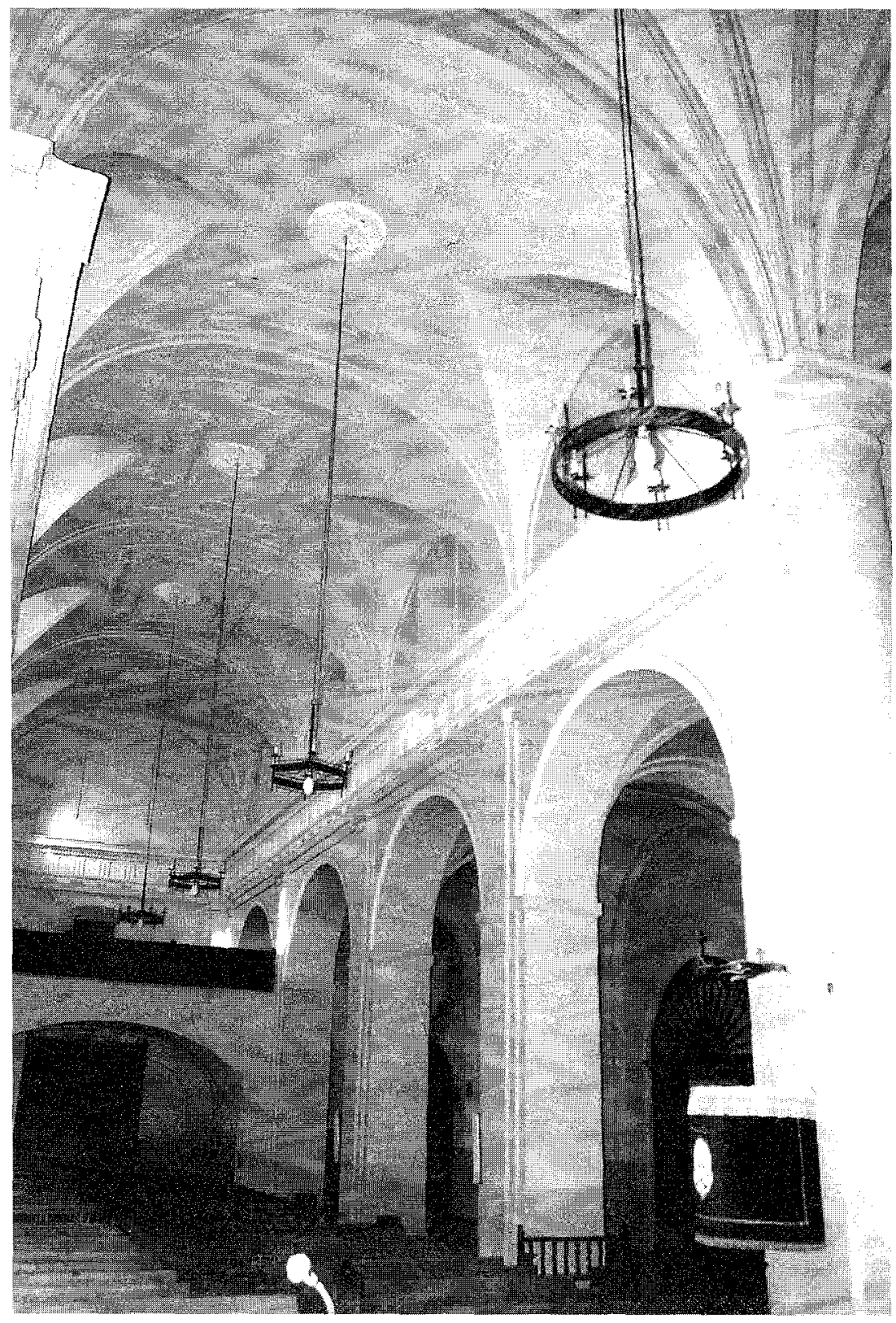

Fig. 3. Interior de la nave central. 
vexa de ángulos acodados para marcar suavemente el claroscuro: una en el costado de mediodía y otra a los pies de la nave principal (no llegada a ejecutar la que se proyectó en el lado norte). Al exterior, contando con el condicionante de la torre preexistente, el arquitecto compuso un hastial rectangular, de gran desarrollo vertical, en un plano más retraído, construido sobre zócalo de granito y todo en ladrillo, entre cuyas dos pilastras se superponen axialmente la portada principal y la ventana del coro, y donde la superficie se activa o almohadilla en campos relievados de original combinación, colocando un frontispicio de traza semicircular con su óculo ovalado y remate en punta triangular (atípica configuración que bien puede deberse a una recomposición posterior que alterase el diseño original) y flanqueado por dos acróteras con pirámide y bola y en el medio una cruz de piedra, hoy perdida. Así pues, a la antigua cabecera de lo que pudo ser iglesia columnaria Fray Lorenzo de San Nicolás arrimó el cuerpo de iglesia que faltaba, embebiendo en gruesos pilares apilastrados la mitad del fuste de los dos grandes soportes dóricos y fabricando así sus tres naves pero a distinta altura en un estilo clasicista de clara ruptura espacial y formal con lo preexistente y convirtiendo la iglesia en un espacio de obligada direccionalidad, de predominante carácter barroco ${ }^{35}$.

En este sentido, este bloque de naves coincide en planteamiento con el proyecto que realizó por esos mismos años (entre 1650 y 1659) para levantar el cuerpo de la iglesia parroquial de Villaseca, insistiendo decididamente en una tipología de iglesia de tres naves con una misma solución arquitectónica, tanto espacial como volumétrica, lo que confirmaría la idoneidad que Fray Lorenzo encontró en este tipo de planta para gran iglesia rural, derivado obviamente del prototipo jesuítico, haciendo de las capillas laterales intercomunicadas verdaderas naves paralelas a la central. Por otro lado, en el tratamiento de las superficies interiores de la iglesia de

\footnotetext{
35. De haberse proseguido en su época y bajo el mismo estilo, la parroquia de Novés se hubiera prolongado en un cuerpo de iglesia de tipo columnario y de salón como lo delata la amplitud de dimensiones de su cabecera, la altura pareja dada a los tres arcos torales y el tipo estilistico de sus soportes cilíndricos, con formalismos a lo romano; si bien, el fondo del presbiterio define un momento gótico tardío, de finales del $\mathrm{s}$, xv, con sus tres paramentos correspondidos con bóvedas triangulares cuyos nervios apoyan en mensulones góticos y un tramo recto cubierto por nervadura de terceletes y ligaduras, cuyos empujes se transmiten a cuatro anchos soportes cilíndricos, los dos interiores todavía gotizantes; pero los del arco triunfal tienen hermoso capitel jónico con acanalado y basa clásica, que anuncian un momento artístico del s. xvi, en reciprocidad con las columnas del crucero, pero éstas con capitel dórico, soportando tres bóvedas de crucería a base de terceletes y sencillos combados. La cabecera es atribuible en parte a Alonso de Covarrubias, maestro mayor de ía catedral de Toledo desde 1534, quien en abril de 1536 veía las condiciones de la capilla mayor que estaba por hacerse en Novés, la cual hubiera seguido una estructura tardogótica de tres naves como la diseñada en 1534 para Yepes, Marías, Fernando: Op. cit., t. I, pág. 220.
} 
Fray Lorenzo de San Nicolás y la iglesia de Novés (Toledo)

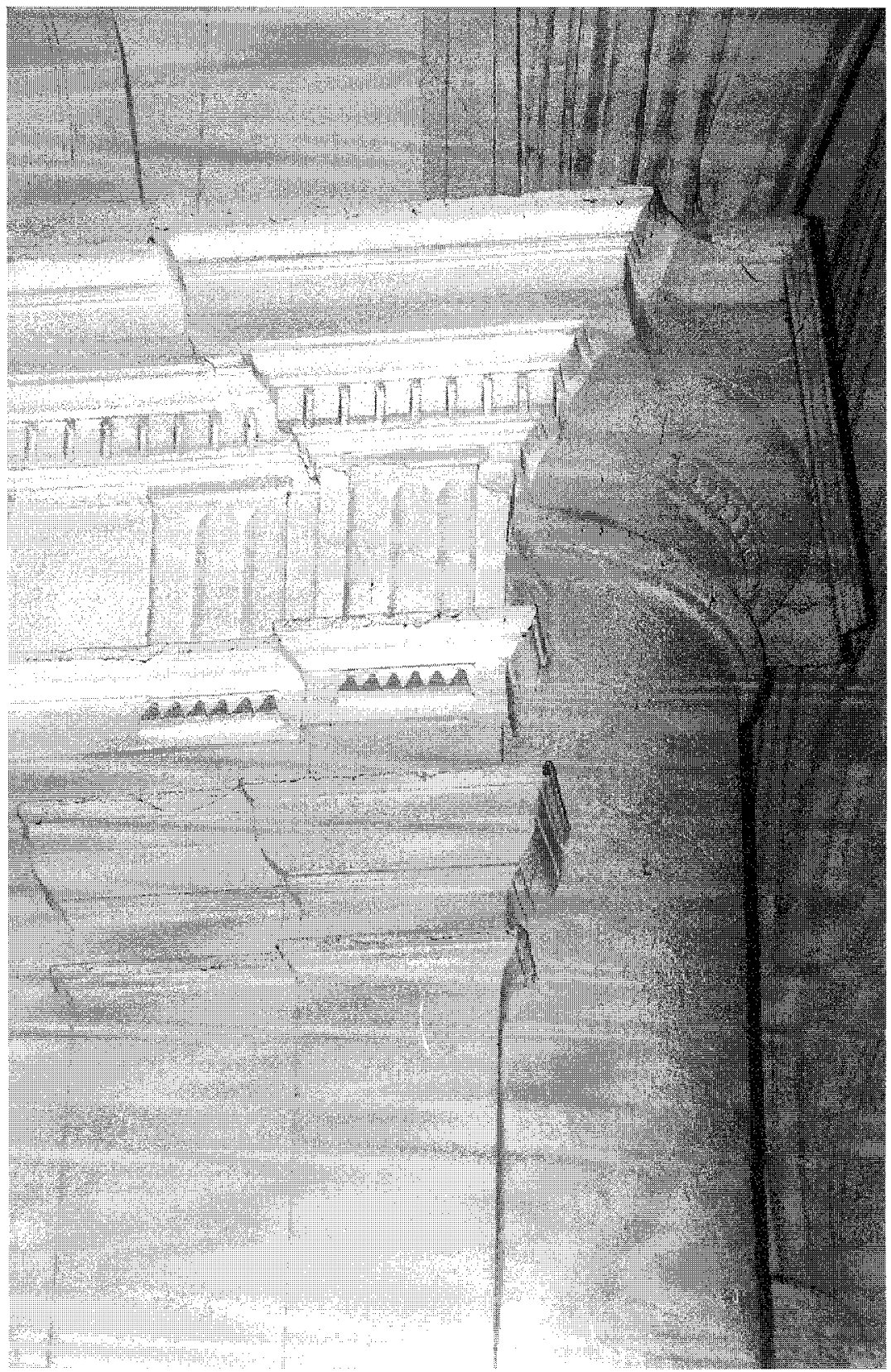

Fig. 4. Detalle del orden dórico. 
Novés el arquitecto se muestra sobrio, dentro de la tradición postherreriana del siglo XVII que tan fuerte se mostraba aún en Toledo, y recurre al mismo orden de pilastras dóricas con friso de triglifos, serie de dentículos y cornisa bien moldurada ya empleado en la iglesia de S. Plácido de Madrid, en la capilla del Amparo y luego en las agustinas de Colmenar de Oreja, en las "Gaitanas" de Toledo y en la capilla del hospital de S. Bernardo de Villaseca de la Sagra, por citar sus obras más próximas en el tiempo a la obra de Novés (Fig. 4). El ornato sólo se aplica en el cañón central con labor de yesería muy escueta y sencilla, lejos de los ricos y complicados diseños geométricos que Fray Lorenzo gustaba reservar para las bóvedas. Esta sobriedad en el uso de moldurajes y yeserías conlleva evidentemente una economía en la obra, lo que nunca es un factor a obviar en el encargo de la edificación por parte del pueblo de Novés. Dos detalles más de cierto ornato son: la concha de yeso que a modo de repisón sostiene el paso externo desde la torre al coro alto y la labor que lleva la bóveda interior de la torre (un octógono central rodeado de cuatro eses, todo encuadrado).

En definitiva, Fray Lorenzo moduló para la iglesia de Novés unas naves dentro de un prisma de acertada proporción, ajustadas inevitablemente a unas pautas determinadas por la altura y medidas del arco toral apuntado que se abre a la nave del centro y, en superficie, por un solar limitado por la torre y la capilla del s. XVI, que acotaban la línea occidental y norte del plano, respectivamente. A su vez, el problema técnico, no tanto el estilístico, que hubo de resolver al embutir los pilares renacentistas y neutralizar los empujes de la crucería gótica responde al buen oficio teórico del arquitecto agustino, que optó por naves laterales de menor altura para asegurar la estabilidad de la fábrica sacrificando correctamente el desarrollo en salón que marcaba el crucero renacentista y determinando una planta de cruz latina.

En el exterior, de claros volúmenes y cuidado aparejo mixto, sobresale obviamente la fachada occidental, que por su decorativismo de superficies activas o en resalto no desmiente la autoría del diseño pues los campos relievados son una constante muy característica en la obra de su promotor el arquitecto agustino por lo que la fachada de Novés desarrolla en una nueva versión modelos anteriores vistos en Talavera, Colmenar de Oreja, Villaseca y Añover o diseños incluidos en su tan difundido tratado Arte y Uso de la Arquitectura.

Fray Lorenzo de San Nicolás alcanza en torno a mediados del siglo XVII el momento más fecundo, sin duda, de su carrera profesional, y ésta, hay que admitirlo, se desarrolla en parte en Toledo aportando indefectiblemente el carácter erudito y cortesano de su arte a la arquitectura local, todavía rendida al conservadurismo clasicista herreriano vigente en Toledo en la primera mitad 
del S. XVII ${ }^{36}$. Su reconocida reputación de arquitecto deriva de su obra escrita como difusor de la buena práctica arquitectónica y, cómo no, de su repertorio de obras ya planteadas ya ejecutadas en las que parte de minuciosos y completos proyectos técnicos acompañados de una precisa evaluación de costes, asistiendo frecuentemente con sus visitas a las obras y asociándose a maestros de probada pericia que secundan correctamente la ejecución de sus planes, quizás no muy ambiciosos cuando se trata de iglesias parroquiales, pero siempre muy personales. En Novés, como se ha visto, impone su idea frente a las competencias profesionales y planteamiento de un maestro mayor y asume la construcción a través de un discípulo, el nombrado Juan de Corpa, con quien acaba de trabajar probablemente años atrás en Colmenar de Oreja, aunque el paso de Corpa por Novés fuera tan breve y accidentado ${ }^{37}$.

Si bien, podemos pensar que la capilla mayor de Ntra. Sra. del Prado en Talavera (1649) responde a un plan grandioso y excepcional para una ermita o santuario mariano, hemos de considerar que es la de Novés la primera iglesia parroquial o, para ser más exactos, el primer plan parcial de parroquia rural que conocemos debido a Fray Lorenzo de San Nicolás, presentado en torno a 1651, y no olvidemos que seguido de uno similar en Villaseca de la Sagra (antes de 1659), eligiendo la tipología adecuada para un gran templo: las tres naves longitudinales. Cuando el arquitecto venía ocupándose mayormente de la construcción de iglesias conventuales, derivándolas en general del tipo carmelitano de una sola nave, el plano de naves de la iglesia de Novés, a pesar de su carácter de parte añadida que completa a un edificio preexistente, demuestra la versatilidad de Fray Lorenzo para conformar soluciones arquitectónicas acordes con la específica y distinta funcionalidad que plantea cada edificación.

36 SuÁrez Quevedo: Op. cit, pág. 103.

${ }_{37}$ Tal vez empezara a trabajar en la capilla de Ntra. Sra. del Amparo, trazada por Fray Lorenzo en 1647, aunque sobre esto no hay dato concluyente, Cruz Valdovinos, J.M.: «Fray Lorenzo de San Nicolás y la capilla de Nuestra Señora del Amparo en Colmenar de Oreja (Madrid)", Gora, núm. 145, 1978, págs. 28-33. Tovar Martin, V.: Arquitectos madrileños de la segunda mitad del s. xvII, Madrid, I.E.M., 1986, pág. 377. El maestro de obras Juan de Corpa (16281695) estuvo estrechamente unido a la figura de Fay Lorenzo de San Nicolás con quien trabajaría en diversas obras. Es más probable que interviniera en la iglesia de $\mathrm{S}$. Plácido de Madrid desde 1655, año de inicio de las obras según AGullo y Cово, M.: «El monasterio de San Plácido y su fundador el madrileño don Jerónimo de Villanueva, Protonotario de Aragón", Villa de Madrid, XIII, $n^{\circ} 47,1975$, pág. 41.

Como arquitecto, Juan de Corpa daba las trazas para la obra de la iglesia madrileña de Portacoeli, hoy parroquia de S. Martín, en 1661, Tovar Martín, V.: «El convento de Ntra. Sra. de Portacaeli y San Felipe Neri de Clérigos Menores de Madrid", A.l.E.M., XX, 1983, pág. 13. Pensamos pues que a raiz de su apartamiento de Novés Corpa pudo emprender estos importantes trabajos y centrar su actividad en la Corte. 
